\title{
A Fazenda Software Educativo para a Educação Ambiental
}

\author{
Alessandro Antunes Silva; Licenciado em Computação, Especialista em Software \\ Educativo - Feevale; aleantunesrs@gmail.com \\ Liliana Maria Passerino; Doutora pelo PPGIE - UFRGS; liliana@ cinted.ufrgs.br
}

The Farm

Educative Software to a Enviromenntal Education

\section{Resumo}

Este artigo apresenta a modelagem de uma aplicação educacional, voltada a Educação Ambiental. Desenvolvido em linguagem Flash com o apoio do software proprietário Google SketchUp, ele é um simulador de uma fazenda, onde o usuário deve gerenciá-la de forma que ela se torne produtiva.

Palavras chave: Sketchup, educativo, jogo, fazenda, flash.

\section{Abstract}

This article shows a project about the construction of a educational software to a Education Enviromental. Development in Flash with Google SketchUp, it is a farm simulator, where the gamer has a control it.

Key words: Sketchup, educative, game, farm, flash.

\section{Introdução}

O uso de Softwares Educativos, em especial de jogos educativos computadorizados no ambiente escolar não tem obtido o sucesso esperado na comunidade acadêmica, sendo que um dos principais problemas encontrados é o baixo grau de imersão, ou seja, o aluno não se sente atraído pelo ambiente desenvolvido. Podemos afirmar isso com base em pesquisas realizadas por Clua, Luca e Nabais (2002) que conduziram uma série de entrevistas com jogadores na faixa etária entre 10 e 17 anos, com o objetivo de identificar o que eles pensavam e esperavam de jogos educativos. O resultado retrata um cenário bastante pessimista em relação ao tema: nenhum dos jogadores entrevistados afirmou que existiam jogos educativos "excelentes", ao passo que 68\% deles consideraram todos os jogos educativos já experimentados como sendo "terríveis". Uma pequena parcela dos entrevistados (5\%) se declararam indiferentes em relação ao tema em discussão e apenas $27 \%$ dos jogadores afirmaram que já jogaram pelo menos um jogo educativo que pudesse ser considerado como "bom".

Com base nessas informações, entendemos que é necessário, criarmos um ambiente que possa atrair a atenção do aluno, para que ele se sinta envolvido, trabalhando elementos lúdicos que promovam a fantasia, a criatividade e o desejo de interagir com o jogo e ao mesmo tempo propiciar condições para a construção de conhecimento. 
Nesse sentido, escolhemos a área de Educação Ambiental por ser este um tema atual e com poucos jogos educativos desenvolvidos. O desafio que se coloca é de formular uma educação ambiental que seja crítica e conscientizadora ao mesmo tempo lúdica e prazerosa. O objetivo é desenvolver um ambiente virtual que permita a visualização, simulação e manipulação de objetos de estudo na educação ambiental.

O objetivo do módulo proposto é utilizar a simulação de ambientes como uma ferramenta de auxílio ao professor e aluno no processo de ensino e aprendizagem, mostrando o funcionamento e gerenciamento de uma fazenda. O software tem caráter multidisciplinar o que permite sua aplicação também em outras áreas como História, Geografia, Ciências, entre outras.

Assim, juntamos dois grandes pontos a serem estudados, a Educação Ambiental e o uso de Jogos Educativos como instrumento de aprendizagem, para desse modo, desenvolver um software do tipo Simulador que possa integrar a Educação Ambiental e promover os alunos da rede de ensino de nível fundamental a refletirem sobre a necessidade de práticas sociais que possam minimizar danos ambientais, simulando através do software experiências de educação ambiental de forma criativa e inovadora.

\section{A Educação Ambiental}

Dentre as transformações mundiais das duas últimas décadas, aquelas vinculadas à degradação ambiental e à crescente desigualdade entre diversas regiões do planeta nos mostram necessidades urgentes de criarmos meios adequados para a formação de um novo cidadão, consciente de suas responsabilidades quanto aos cuidados ambientais. $\mathrm{O}$ alarme dado pelos fenômenos de aquecimento global, destruição da camada de ozônio, a contaminação dos rios, dentre outros problemas, nos revela que o impacto da sociedade sobre o meio ambiente tem tido conseqüências cada vez mais importantes e severas, tanto quantitativas como qualitativas.Além disso, dados do Programa da ONU para o Meio Ambiente (PNUMA) revelam que um quarto das mortes ou casos de invalidez por doenças infecciosas registrados no mundo estão relacionadas à degradação ambiental. (Ecofalante, 2007)

Assim, cabe ressaltar que a educação ambiental assume cada vez mais uma função remodeladora, transformadora de noções e em conseqüência do ambiente, em que a responsabilização do indivíduo é imprescindível para promovermos um novo tipo de desenvolvimento, a qual chamamos de desenvolvimento sustentável.

A noção de desenvolvimento sustentável refere-se à necessária redefinição das relações entre sociedade humana e a natureza, e, portanto, a uma mudança substancial do próprio processo civilizatório, introduzindo o desafio de pensar a passagem do conceito para a ação. (Jacobi, 1997).

Depois da Conferência Intergovernamental sobre Educação Ambiental realizada em Tbilisi (EUA), em 1977, iniciou-se um processo em nível global para criar condições que formem uma nova consciência sobre o valor da natureza e para orientar a produção de conhecimento baseada nos métodos da interdisciplinaridade e nos princípios da complexidade. Esse campo educativo tem se desenvolvido, e isso tem possibilitado a realização de experiências concretas de educação ambiental de forma criativa e inovadora por diversos segmentos da população e em diversos níveis de formação. O documento da Conferência Internacional sobre Meio Ambiente e Sociedade, Educação e Consciência Pública para a Sustentabilidade, realizada em Tessalônica (Grécia), chama a atenção para a necessidade de se criarem ações de educação ambiental baseadas nos conceitos de ética e sustentabilidade, identidade cultural e diversidade, mobilização e participação e práticas interdisciplinares (Sorrentino, 1998).

A educação ambiental é uma área interdisciplinar na qual participam história, 
geografia, biologia, física, química, ciências sociais, entre outras. Por esse motivo, pensar no uso das TICS (Tecnologias da Informação e Comunicação) nessa área leva necessariamente a pensar na utilização de ambientes visualmente ricos e com possibilidades de simulação, ou seja, dinâmicos.

\section{O software educativo}

É um ambiente de aprendizagem que une as características de um jogo com as de um software. O ensino, ao utilizar meios lúdicos, cria um ambiente gratificante para o desenvolvimento integral da criança. De acordo com Piaget (1976), "o jogo consiste em satisfazer o eu por meio de transformação do real em funções dos desejos" (p.56), assim, tem como função assimilar a realidade.

Os jogos devem ser elaborados de acordo com a faixa etária do público a qual se destinam. Propiciando o desenvolvimento do raciocínio lógico de uma forma lúdica, sendo um excelente vínculo de difusão e treinamento de habilidades como coordenação motora, memorização, motivação, entusiasmo, concentração, destreza entre outros.

RIZZO (1988, p.48) afirma que:

"Os jogos constituem um poderoso recurso de estimulação do desenvolvimento integral do educando. Eles desenvolvem a atenção, disciplina, autocontrole, respeito a regras e habilidades perceptivas e motoras relativas a cada tipo de jogo oferecido. Os jogos podem ser trabalhados de forma individual ou coletiva, sempre com a presença do educador para estimular todo o processo, observar e avaliar o nível de desenvolvimento dos educandos e diagnosticar as dificuldades individuais, para poder produzir estímulos adequados a cada um. 'Não há momentos próprios para desenvolver a inteligência (...) sempre é possível progredir e aperfeiçoar-se. Os jogos devem estar presentes todos os dias na sala de aula".

Os jogos educativos dispõem de grandes informações, representadas de maneiras diversas, através de imagens, textos, sons, filmes etc. Buscam diversão e entretenimento. "O jogo aparece quando a criança abandona sua fase egocêntrica possibilitando desenvolver os relacionamentos afetivo-sociais" (Piaget, 1976, p.48).

Atualmente, a informação assume um papel cada vez mais importante, com o grande crescimento da Internet, multimídia, do ciberespaço, a educação para a cidadania representa a possibilidade de motivar e sensibilizar as pessoas em transformar as diversas formas de participação na defesa da qualidade de vida. Assim, a educação ambiental assume cada vez mais uma função transformadora, na qual a educação e responsabilização dos indivíduos torna-se um objetivo essencial para promover o desenvolvimento sustentável. Dessa forma, a educação ambiental é condição necessária para modificar um quadro de crescente degradação sócio-ambiental e o educador terá uma função de mediador nessa construção de referenciais ambientais e deverá saber usá-los como instrumentos para o desenvolvimento de uma prática social centrada no conceito da natureza.

Pensando assim, o ambiente virtual criado para a aprendizagem, deverá contemplar esses objetivos, servindo de ferramenta de transformação e porque não dizer, evolução, no sentido de que, através do ambiente desenvolvido e da interação do usuário, poderemos fazer com que haja um encontro entre uma real necessidade de educação ambiental sem deixar de lado o conceito de entretenimento a qual o conceito de jogo computadorizado traz.

A rigor, para ser chamado de "simulador", um determinado sistema deveria atender aos requisitos máximos de precisão quanto aos fenômenos que se tenha a intenção de levar ao virtual. Mas se considerarmos que os requisitos de simulação para jogos são diferentes, com menos exigência de precisão, podemos aceitar a categoria "jogos de simulação". Galvão (2000) se reporta a Society of Advancement of Games 
and Simulation in Education and Training, que estabelece o conceito de simulação como uma representação funcional da realidade, podendo ser um modelo de processo simplificado, para dar a sua definição de jogo de simulação: "uma mistura entre as características de um jogo - competição, cooperação, regras etc - com aquelas de um simulador, que é a incorporação de características críticas da realidade".

Desta forma o software "A Fazenda" vem como uma solução a ser utilizado no ambiente escolar, como uma ferramenta de apoio ao professor e ao aluno.

Como o processo escolar é influenciado diretamente pelo meio social e pelo avanço técnico-científico, em especial a chamada cibercultura, é necessário definir metodologias que permitam superar esses novos desafios. Assim, construímos uma proposta nova e diferenciada através da modelagem deste software.

\subsection{Aspectos Educacionais no uso do Software}

Crianças com um grau maior de dificuldades de aprendizagem podem se beneficiar da aprendizagem com caráter lúdico, descontraído. $\mathrm{Na}$ maioria das vezes observam-se, neste contexto, experiências positivas com softwares educativos, que fazem com que a criança ou adolescente passem a ter um desenvolvimento cognitivo maior e a melhorar seu comportamento na escola.

Podemos citar alguns simuladores de grande sucesso comercial como o "The Sims", que teve seu lançamento no início de 2000. O jogo alcançou um sucesso tão grande em todo o mundo que foi apontado pelo instituto de pesquisas norte-americano PC Data como um dos títulos mais vendidos do mesmo ano na categoria de jogos para computador. Em março de 2002, a empresa fabricante, a Electronic Arts, anunciou que o The Sims já era o jogo para PC mais vendido de todos os tempos. Na base desse sucesso, está o fato de que no The Sims o jogador possui um controle total do cenário, podendo comandar a vida de pessoas virtuais, construir suas casas e controlar desde suas carreiras profissionais até as atividades mais básicas do dia-a-dia, como tomar banho ou cozinhar.

Dois anos depois, em setembro de 2004, foi lançado o The Sims 2, seguindo a estrutura básica do anterior, mas com um ambiente totalmente em 3D. A empresa Eletronic Arts utilizou várias sugestões dos jogadores para aprimorar o game, incluindo a possibilidade dos personagens envelhecerem e transmitirem suas características genéticas para seus filhos.

Em 2006 ganhou destaque na internet o "Second Life", um mundo virtual que, no início de 2007, possuía uma "população" de 2, 8 milhões de habitantes, dos quais 80 mil brasileiros (WIZIACK, 2007, p.76). Criado pelo físico americano Phillip Rosendale, SL é uma comunidade virtual onde quem entra pode virtualmente ser o que bem entender e fazer o que quiser. Segundo a revista Istoé (WIZIACK, 2007), ao entrar no SL, se cadastrar e pagar uma taxa de uso, o freqüentador ganha um avatar, um ser virtual que irá representá-lo no universo virtual.

A nosso ver, a meta principal do educador é engajar os aprendizes como agentes e arquitetos de sua própria educação. Dessa forma, o maior desafio dos jogos educacionais é oferecer para o aluno um ambiente que propicie a interação imersiva. Procurando desenvolver um ambiente onde os usuários queiram estar, explorar e aprender da mesma forma que fazem nos jogos eletrônicos comerciais.

Pensando assim, o jogo educativo deve seguir também o caminho do sucesso dos chamados jogos comerciais pelo fato que estes permitem uma maior imersão, uma exploração do espaço e permite que o aprendiz interprete um personagem e explore um mundo virtual.

A interação com os colegas também influencia positivamente o processo de aprendizagem do aluno e tal interação pode ser potencializada pelo uso em conjunto de softwares educativos. Hoje a escola tem um papel fundamental na socialização. Nela se 
dá o encontro entre a tradição de uma cultura e a realidade do cotidiano das crianças e adolescentes. Assim, o professor tem o papel explícito de interferir no processo, diferentemente de situações informais nas quais as crianças aprendem por imersão em um ambiente cultural. Vemos também que já há uma grande necessidade no mercado por novos programas, o que determina que deverá haver uma necessidade de crescimento na produção de softwares educativos.

Piaget (1974) afirma que a atividade lúdica é o berço obrigatório das atividades intelectuais da criança. Não se trata de uma forma de desafogo ou entretenimento para gastar a energia das crianças, mas de meios que contribuem e enriquecem o desenvolvimento intelectual. Ele afirma:

\begin{abstract}
"O jogo é, portanto, sob as suas duas formas essenciais de exercício sensório-motor e de simbolismo, uma assimilação da real à atividade própria, fornecendo a esta seu alimento necessário e transformando o real em função das necessidades múltiplas do eu. Por isso, os métodos ativos de educação das crianças exigem todos que se forneça às crianças um material conveniente, a fim de que, jogando, elas cheguem a assimilar as realidades intelectuais que, sem isso, permanecem exteriores à inteligência infantil".
\end{abstract}

Assim, desenvolvemos este software educativo, de forma que desperte o interesse pela interação e a socialização, aliada a construção de novos conhecimentos. Por meio do apoio de outras crianças haveremos de despertar a zona de desenvolvimento proximal do aluno e fazer com que este crescimento se dê de forma concreta e satisfatória.

O software desenvolvido é um Simulador, um ambiente virtual, onde o usuário faz o papel de um fazendeiro e terá que administrar sua fazenda, comprando sementes, galinhas, adubo e agrotóxicos na cidade, para então as utilizar em sua fazenda, tentando com isso, torná-la produtiva.

Os estilos cognitivos que serão contemplados neste software, conforme Bandler e Grinder (1982) serão principalmente o visual, auditivo e sinestésico. Procurando assim, desenvolver a memória, atenção e a percepção.

\title{
4. Apresentação do Software
}

O software desenvolvido em Flash 8, possui uma interface agradável e leve, sendo possível até mesmo seu uso na Internet. Além disso, é desafiador, pois traz como personagem central o fazendeiro, comandado pelo usuário o qual tem como tarefa desenvolver sua Fazenda, comprando insumos na cidade, retornando a fazenda, plantando de acordo com as estações do ano, servindo ração às galinhas de seu galinheiro e revendendo seu produto na cidade para conseguir mais dinheiro e em conseqüência, aumentando seu lucro e mantendo a fazenda produtiva.

O software foi desenvolvido com o apoio do Flash 8.0 para sua programação e o desenho de alguns modelos. Além disso, utilizamos o Google Sketchup para a modelagem das casas e prédios, ruas, automóveis e também de algumas plantas. Também foram coletados Gifs animados para serem adicionados ao cenário, como o coelho, pássaro, gato, borboleta e beija-flor. A Wikipédia, enciclopédia virtual livre, foi utilizada para a pesquisa dos diferentes tipos de legumes e frutas que poderiam ser plantados na fazenda. Buscou-se identificar quais eram suas principais características, como nome científico, origem, composição, propriedades, época de plantio, entre outros.

O simulador, "A Fazenda" se mostra um jogo ao mesmo tempo simples e empolgante, educativo e agradável, pois traz em sua estrutura elementos de nosso país, em sua música, seus personagens um tanto estereotipados, as plantas e frutas que são 
compradas e plantadas na fazenda, as galinhas caipiras, entre outros. Faz com que o aluno passe por um processo de descobertas e desafios, aprendendo e se divertindo ao mesmo tempo, tentando assim, manter "viva" sua fazenda.

\subsection{Algumas Telas do Software}

Vemos na figura 6, logo abaixo, a entrada para o jogo, com opções para "Novo Jogo", "Instruções", "Procurar Jogo" e "Sair". É a tela de início, onde o usuário tem uma visão geral do jogo, com instruções para sua utilização.

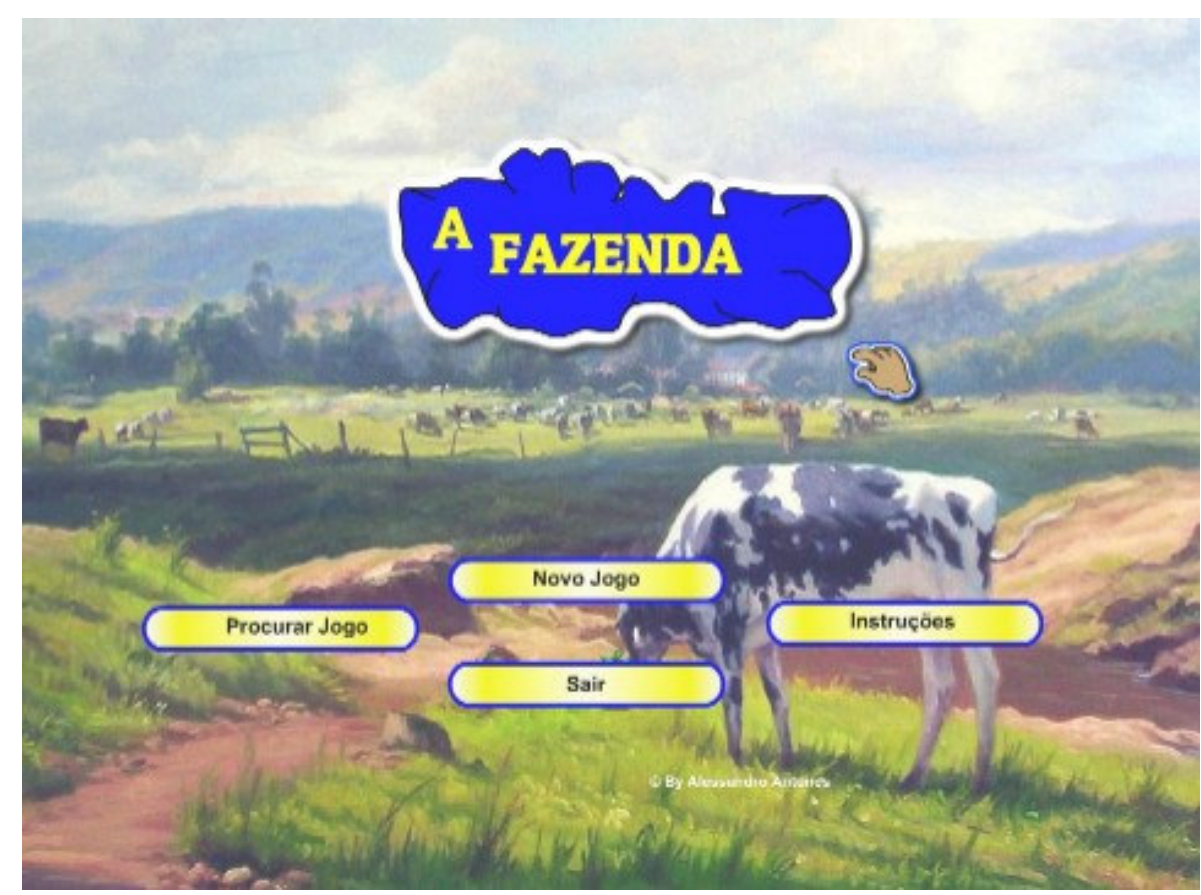

Figura 1: Tela inicial, onde se encontram as opções principais do jogo.

A seguir, apresentamos a tela do jogo onde o personagem, controlado pelo usuário se encontra em sua fazenda. 

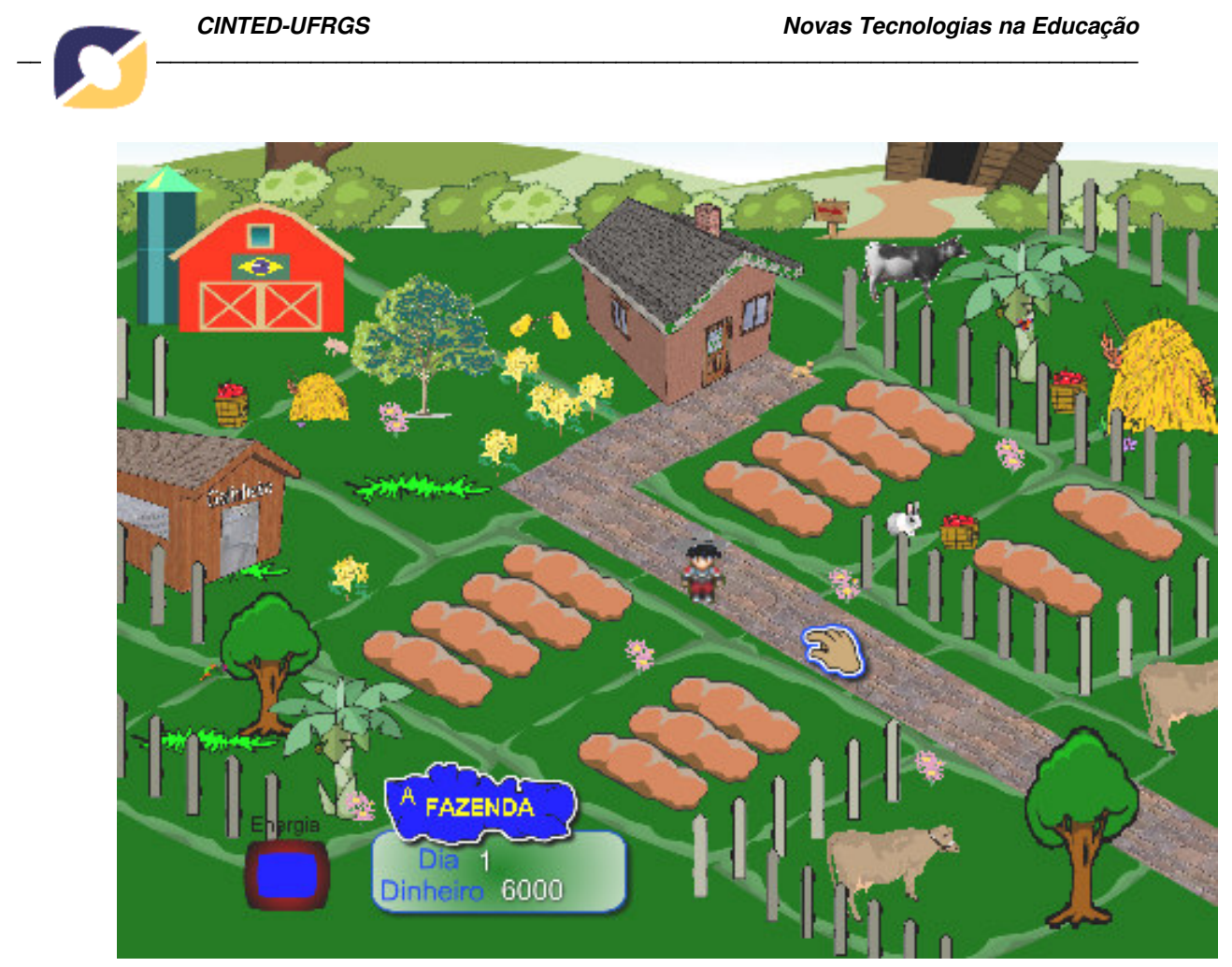

Figura 2: A Fazenda e o fazendeiro comandado pelo usuário.

Movendo o cursor (mão) para o final da estrada, ele leva o usuário para a cidade, onde poderá adquirir sementes, agrotóxicos, adubo, galinhas, entre outros para sua fazenda.

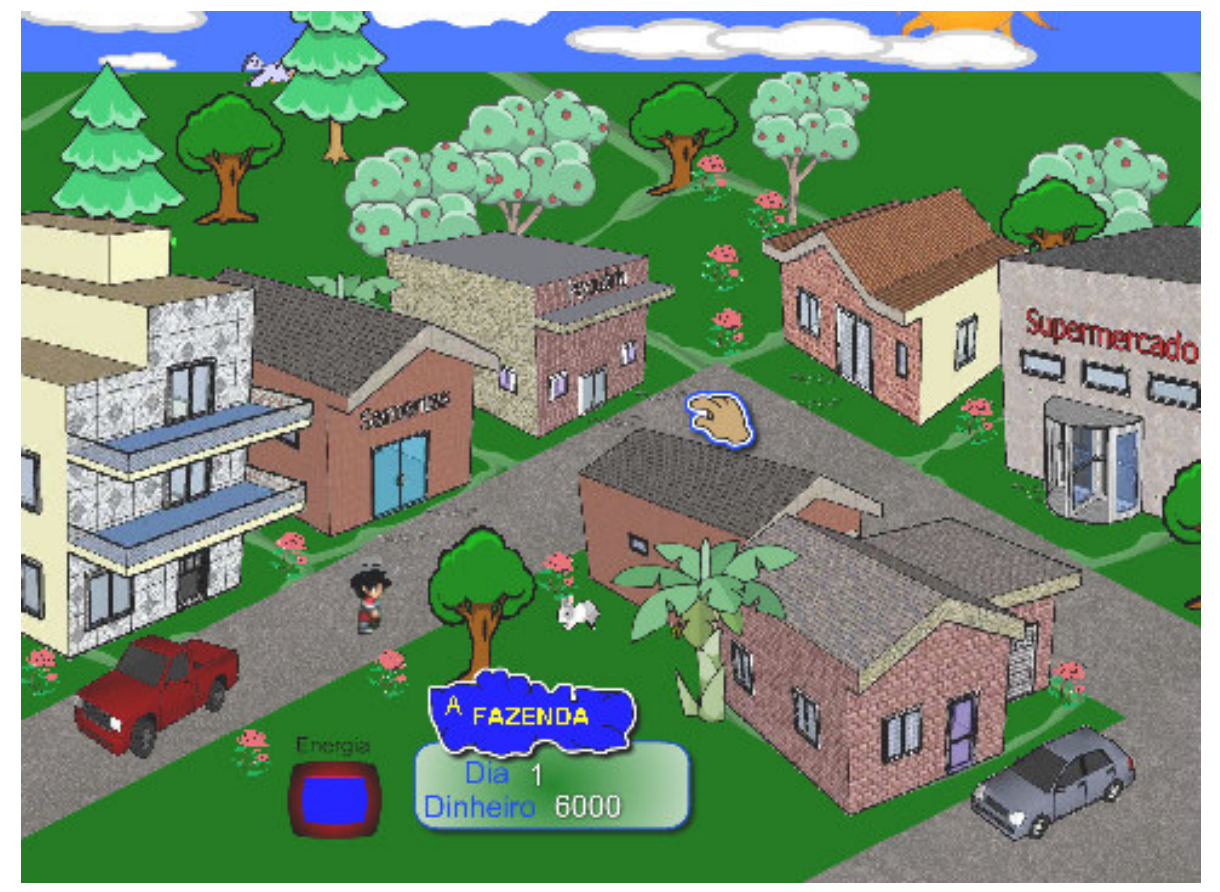

Figura 3: A cidade e as lojas onde o fazendeiro pode comprar o que necessita.

A seguir, vemos a tela da "pecuária", onde o usuário poderá adquirir, caso tenha dinheiro suficiente, galinhas e alimento para elas. 

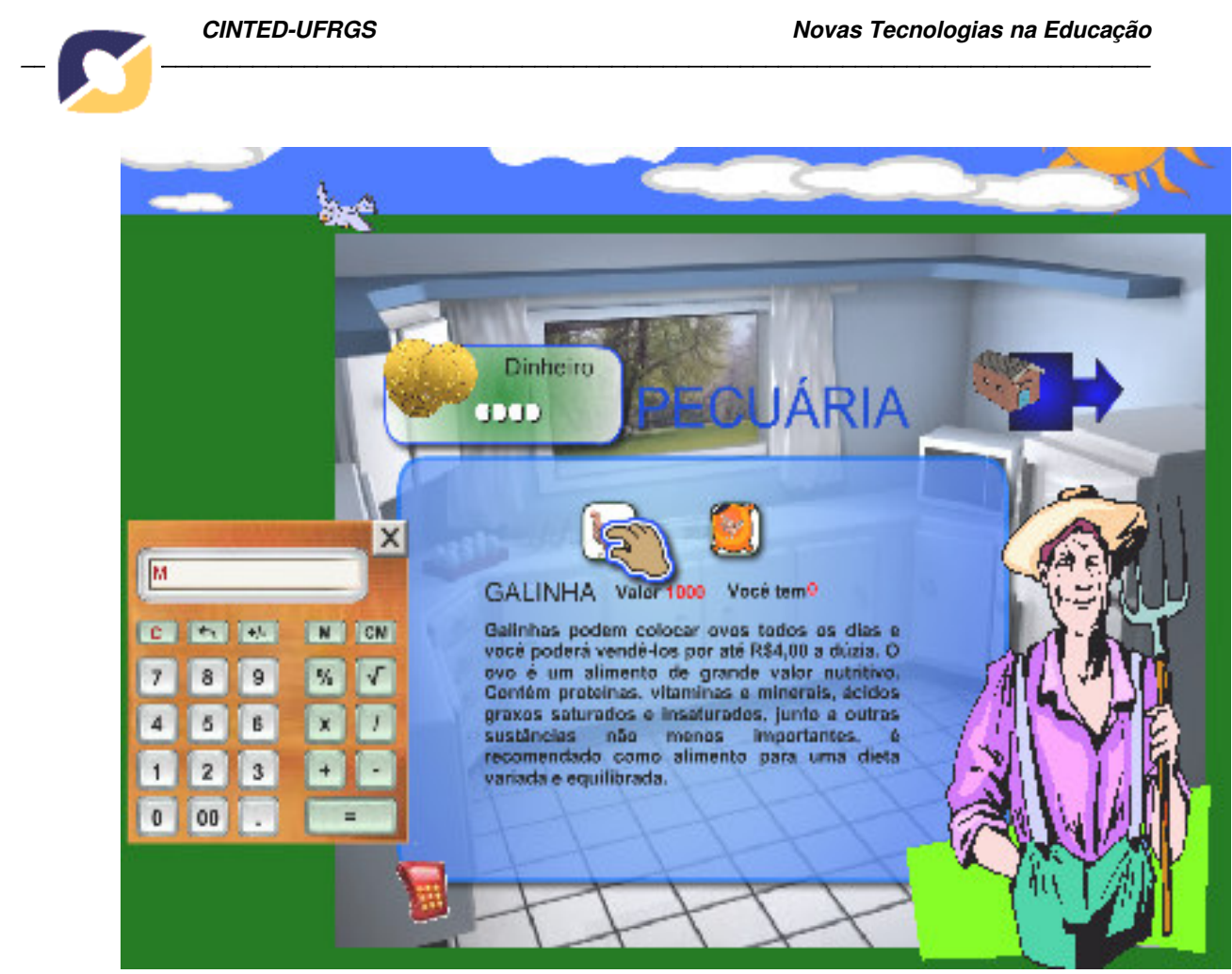

Figura 4: A pecuária onde vemos também a calculadora, que pode ser utilizada pelo usuário para verificar quando dinheiro irá sobrar após a compra ou quanto ele poderá adquirir.

\section{Considerações finais}

A Fazenda foi um software que implicou o estudo de ferramentas para construção das mais diversas, desde as mais simples as mais complexas. Que exigiu muitas horas de estudo e dedicação para que resultasse num trabalho completo, dentro das possibilidades e limitações da ferramenta utilizada para sua construção e que se transformou num software atual, bonito em seu design, atrativo e desafiador. Testes de uso foram realizados no Colégio Sinodal Tiradentes e Escola São Luis, em turmas de $4^{\text {a }}$ série, onde os estudantes puderam utilizar o software, fazendo questionamentos e observações sobre ele.

O software "A Fazenda" é apenas a etapa inicial de um projeto maior, no qual se buscará o desenvolvimento de um mundo virtual em três dimensões onde o usuário poderá "navegar" como se estivesse inserido neste ambiente. Para isso procuraremos o estudo de ferramentas como o "Torque 3D" para a construção de mundos virtuais e a modelagem de personagens mais reais, que possam interagir com o usuário.

Assim, através desde trabalho, conseguimos entender um pouco, não só da problemática ambiental, mas também, entender, que pequenas iniciativas como essa, podem mostrar uma visão de um objetivo mais nobre para os jogos digitais que não seja simplesmente a diversão de nossos alunos.

\section{Referencial Bibliográfico}

BANDLER, R. \& Grinder, J. Sapos em Príncipes. Editora Summos, São Paulo, 1982. 
BITTENCOURT, João Ricardo. GIRAFFA, Lucia Maria. Modelando Ambientes de Aprendizagem Virtuais utilizando Role-Play-Games. Simpósio Brasileiro de Informática na Educação - "Inclusão digital como instrumento de inclusão social”. Rio de Janeiro. Universidade Federal do Rio de Janeiro. 2003

BRENELLI, Rosely P. O jogo como espaço para pensar. Editora Papirus, São Paulo, 2003.

CLUA, E. W. G., Luca Jr., C. L., Nabais, R. J. M. "Importance and Impacts of Educational Games in Actual Society", Wjogos 2002.

DIAS, Genebaldo F. Educação Ambiental: Princípios e Práticas. Editora Gaia, São Paulo, 1998.

GALVÃO, J. R. Modeling Reality with Simulation Games for a Cooperative Learning. in: Proceedings of the 2000 Winter Simulation Conference. 2000.

GRYNSZPAN, Danielle. Educação em saúde e educação ambiental: uma experiência integradora. Rio de Janeiro 1999.

JACOBI, P. et al. (orgs.). Educação, meio ambiente e cidadania: reflexões e experiências. Editora SMA, São Paulo, 1998.

NAIME, Roberto; Garcia, Ana C. de Almeida. Percepção Ambiental e Diretrizes para Compreender a Questão do Meio Ambiente. Editora Feevale, Novo Hamburgo, 2004.

PASSERINO, L.M. (1998). Avaliação de jogos educativos computadorizados.

Disponível em: <http://www.c5.cl/tise98/html/trabajos/jogosed/>. Acesso em: 25 de agosto de 2007.

PRENSKY, Marc. Digital Game-Based Learning. McGraw-Hill, 2001.

PIAGET, Jean. A equilibração das Estruturas Cognitivas - Problema Central do Desenvolvimento. Editora Zahar. Rio de Janeiro, 1976. 
PIAGET, J \& Inhelder, B. Da lógica da criança à lógica do adolescente. Editora Zahar. Rio de Janeiro, 1974.

PIAGET, J.; Inhelder, BÄRBEL. A psicologia da criança. Editora Difel, Rio de Janeiro, 2003.

PICK-UPAU. Panorama Ambiental. Disponível em < $\underline{\text { http://www.pick- }}$ upau.org.br/panorama/2006/2006.10.27/desastre_ambiental_rio_sinos.htm>. Acesso em 29 de julho de 2007.

REDE RPG. RPG Notícias. Disponível em: <http://www.rederpg.com.br>. Acesso em 28 de julho de 2007.

RIZZO, Gilda. Jogos Inteligentes: a construção do raciocínio na escola natural. Editora Bertrand Brasil, Rio de Janeiro, 1996.

SORRENTINO, M. De Tbilisi a Tessaloniki, a educação ambiental no Brasil. In: JACOBI, P. et al. (orgs.). Educação, meio ambiente e cidadania: reflexões e experiências. Editora SMA, São Paulo, 1998. P.27-32.

WIKIPEDIA. Enciclopédia Virtual. <http://www.wikipedia.org>. Acesso em 02 de agosto de 2007.

WIZIACK, Julio. “A segunda vida - por que milhões de pessoas embarcam no mundo

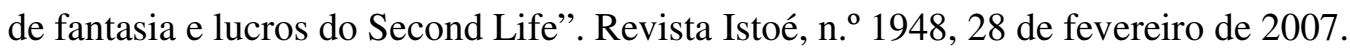

